\title{
Happier during lockdown: a descriptive analysis of self-reported wellbeing in 17,000 UK school students during Covid-19 lockdown
}

\author{
Emma Soneson ${ }^{1}\left[\right.$ - Stephen Puntis ${ }^{2} \cdot$ Nikki Chapman $^{3} \cdot$ Karen L. Mansfield $^{2} \cdot$ Peter B. Jones $^{1} \cdot$ Mina Fazel $^{2}$
}

Received: 10 August 2021 / Accepted: 19 December 2021

(c) The Author(s) 2022

\begin{abstract}
Relatively little research has focused on children and young people (CYP) whose mental health and wellbeing improved during Covid-19 lockdown measures. We aimed to (1) determine the proportion of CYP who self-reported improvement in their mental wellbeing during the first Covid-19 lockdown and (2) describe the characteristics of this group in relation to their peers. We conducted a descriptive analysis of data from the 2020 OxWell Student Survey, a self-report, cross-sectional survey of English CYP. A total of 16,940 CYP primarily aged 8-18 years reported on change in mental wellbeing during lockdown. We characterised these CYP in terms of school, home, relational, and lifestyle factors as well as feelings about returning to school. One-third (33\%) of CYP reported improved mental wellbeing during the first UK national lockdown. Compared with peers who reported no change or deterioration, a higher proportion of CYP with improved mental wellbeing reported improved relationships with friends and family, less loneliness and exclusion, reduced bullying, better management of school tasks, and more sleep and exercise during lockdown. In conclusion, a sizeable minority of CYP reported improved mental wellbeing during lockdown. Determining the reasons why these CYP felt they fared better during lockdown and considering how these beneficial experiences can be maintained beyond the pandemic might provide insights into how to promote the future mental health and wellbeing of school-aged CYP. All those working with CYP now have an opportunity to consider whether a systemic shift is needed in order to understand and realise any learnings from experiences during the pandemic.
\end{abstract}

Keywords Mental health $\cdot$ Wellbeing $\cdot$ Young people $\cdot$ School $\cdot$ Covid- $19 \cdot$ Lockdown

\section{Introduction}

The extensive and indiscriminate societal changes during the Covid-19 pandemic have significantly impacted the lives of children and young people (CYP). Whilst the rates of infection and public health responses to the pandemic have differed across time and place, widespread school closures and social distancing measures have interrupted

Peter B. Jones and Mina Fazel are joint last authors.

Emma Soneson

es703@medschl.cam.ac.uk

1 Department of Psychiatry, University of Cambridge, Douglas House, 18b Trumpington Road, Cambridge CB2 8AH, UK

2 Department of Psychiatry, Warneford Hospital, University of Oxford, , Oxford OX3 7JX, UK

3 Fresh+ Group, Fresh CAMHS Liverpool, Catkin Building, Alder Hey Children's NHS Foundation Trust, Eaton Road, Liverpool L12 2AP, UK
CYP's education and disturbed their social milieu across the globe, altering the way they interact with those around them. Several studies have offered insight into the impact the pandemic has had on CYP's mental health and wellbeing, mostly reporting on its negative mental health consequences. For example, in July 2020, as public health measures from the first United Kingdom (UK) lockdown were starting to ease and the school year was ending, the English national survey of approximately 3500 CYP showed that one in six CYP aged 5-16 years had a clinically diagnosable mental health disorder, representing an increase from one in nine in 2017 [1]. Evidence from a longitudinal study of approximately 60,000 young people aged $13-18$ years in Iceland also demonstrated increases in average levels of depressive symptoms and decreases in mental wellbeing during September-November 2020, when the country had strict physical distancing measures and most schools were limited to online provision, as compared with 2016 and 2018 [2]. Smaller studies from England, the Netherlands, the United States, and Australia that have compared pre-pandemic data 
with data collected in March-May 2020, when each country was experiencing lockdown measures and school closures, also provide evidence for deterioration in various domains of CYP's mental health [3-6].

This picture of deterioration is, however, far from uniform. Some studies have found little to no change in average levels of CYP's mental health or report deterioration only in select domains $[3,7]$. Of note, two studies have reported improvement in the average levels of CYP's mental health and wellbeing during the pandemic. First, Widnall and colleagues [8] followed a group of approximately 1000 English 13- to 14-year-olds from October 2019 to April/May 2020, when the UK had strict lockdown measures and school closures. The authors found an increase in wellbeing and decrease in risk of anxiety, with the greatest improvements for those who had poor pre-pandemic mental health and wellbeing and low connectedness with school, peers, and family. Second, Penner and colleagues [9] reported improved mental health in a sample of over 300 American 10-14-yearolds followed from January 2020 to April/May 2020, when the country had stay-at-home measures and schools were limited to online provision. The $20 \%$ of their sample who had poor mental health pre-pandemic experienced clinically significant improvements in internalising, externalising, and total problems scores. Among the rest of the sample, there were statistically (though not clinically) significant improvements in internalising and total problems.

Furthermore, within several of the studies that showed an average deterioration in levels of mental health and wellbeing, there have been subgroups of CYP who either improved or did consistently well during the pandemic. In the English national survey (described above), just over one-quarter of CYP aged 11-16 years reported that lockdown had made their life better [1]. Findings from the UK Co-SPACE study, which includes repeated data from approximately 3000 parents and CYP (with no prepandemic data), also highlighted subgroups of CYP who had consistently lower-than-average symptoms of conduct, hyperactivity, and emotional problems in the first months of the pandemic (March-July 2020), and, in the case of emotional problems, a sub-group that improved over time [10]. Another cross-sectional study of approximately 1000 Canadian CYP aged 6-18 years in April-June 2020, during Canada's emergency public health measures including school closures, found that $20 \%$ had experienced a parentreported improvement in at least one of six domains of mental health: depression, anxiety, irritability, attention, hyperactivity, and obsessions/compulsions [11]. Among participants aged 10-12 years, 9-13\% self-reported improvements across five domains of mental health, as did $8-20 \%$ of those aged $13-18$ years. For both age groups, the greatest improvements were in the depression and anxiety domains. Improvements in these domains were associated with having a pre-pandemic psychiatric diagnosis and less stress from social isolation.

In addition to quantifying improvements in mental health and wellbeing, it is important to better understand some of the reasons behind these improvements. A number of qualitative studies conducted in the UK, United States, Ireland, and Portugal have explored CYP's experiences of the pandemic between May and October 2020, during which time there was significant variation in Covid-related public health measures and restrictions [12-15]. Whilst most of the narratives in these studies were primarily centred around negative impacts (e.g. disruptions to schooling or social networks, deterioration in mental health), some CYP cited positive changes. These changes were related to school (e.g. enjoyment of self-directed learning [12], less schoolwork, less stress and pressure from school and activities [15]), relationships (e.g. strengthened family bonds [15, 16], avoiding unwanted interactions at school [15]), and having more autonomy over their schedule and activities (e.g. more time to pursue hobbies [12, 14, 15]). Stallard and colleagues [17] specifically aimed to explore positive changes related to the pandemic. In their survey of 385 parents and carers with children aged 6-16 years in Portugal and the UK, conducted during each country's first lockdown in May-June 2020, the authors asked participants to list 'any positives' to come out of the pandemic and social distancing measures. Nearly nine in ten provided a response, which fell under categories related to interpersonal relationships (e.g. improved relationships with family), appreciation of life (e.g. opportunity to assess personal values, ability to live a healthier life), new possibilities (e.g. learning new skills, better work-family balance, changes to their children's education), and spiritual growth (e.g. positive social and environmental changes). Whilst the answers were from a parent/carer perspective, many responses related to the family or home environment, and, therefore, of likely relevance to CYP.

Overall, there has been insufficient focus on CYP who have experienced improved mental health and wellbeing during the pandemic, especially in terms of studies that have analysed data gathered directly from CYP. Identifying the specific factors that may have contributed to improved mental health and wellbeing provides the opportunity to understand how we can create lasting positive change to promote better mental health and wellbeing post-pandemic [18], which might have impact beyond just those CYP who have reported improvements in lockdown. In this study, we aimed to (1) determine the proportion of CYP who selfreported improvement in their mental wellbeing during the first Covid-19 lockdown and (2) describe the characteristics of this group in relation to their peers. 


\section{Methods}

\section{Data source: OxWell Student Survey}

This study used data from the OxWell Student Survey, a recurring, cross-sectional, self-report survey that includes variables relating to CYP's mental health and wellbeing [19-21]. The survey contains a set of 'core' questions repeated in each survey iteration as well as new questions added in response to social and environmental events (e.g. the Covid-19 pandemic) and emerging research hypotheses. Students, parents, teachers, and health commissioners provide input on the survey to ensure its quality and relevance [21].

\section{Context: 2020 data collection}

For this analysis, we used data collected in June-July 2020, during the first round of partial school closures due to the Covid-19 pandemic. On 26 March 2020, the first national lockdown came into effect. Lockdown measures included a 'stay at home' order and closure of all nonessential businesses and organisations. Measures also included school closures for all CYP except those whose parents were classified as essential (key) workers (e.g. health care workers, law enforcement, and others responsible for delivering the Covid-19 public health response) and those considered 'vulnerable' (e.g. CYP under the care of statutory/social services because of family difficulties, CYP with mental health concerns, and CYP in families or social situations deemed by schools to be of concern and, therefore, in need of support over the lockdown) [22]. From 1 June 2020, CYP in year groups preparing for transitions or national exams (English school years 6, 10, and 12) were also eligible to receive in-school provision [19]. Not all CYP eligible for an in-school place used the place, for a variety of reasons, for example, that they were able to be cared for at home by other family members or they did not like the school experience, which would have been very different to their usual schooling. CYP not in school received at-home education provision, which varied widely across schools and households [19]. It is estimated that around 10-15\% CYP were actually attending in-school provision during the survey period [23].

\section{Participants}

Mainstream primary and secondary schools and further education colleges (FECs) in the south of England were eligible to participate. Our analysis includes students in
Years 4-13 (primarily aged 8-18 years) at state-maintained and independent primary and secondary schools and FECs located primarily in Oxfordshire, Berkshire, Buckinghamshire, and Gloucestershire.

\section{Recruitment}

In May to July 2020, local authorities sent e-mails to schools in their catchment areas to invite them to participate in the study. The OxWell team sent study information to the schools that registered to participate, which then sent study information to parents. Schools enrolled students under the age of 16 years using a parental opt-out model, and those aged 16 years and older gave their own active, informed consent to participate. Schools provided students with secure log-in details where they could read about the survey and provide assent (all students) and full consent (students aged $\geq 16$ years) before participating. This is described in greater detail in the study protocol [21].

\section{Survey measures}

\section{Measure selection}

To ensure that we included the most relevant and meaningful variables available within the OxWell Survey in our analyses, we consulted with parents and CYP to understand what factors they thought might influence whether a student experienced improved mental wellbeing during lockdown. To this end, we created a questionnaire (the "stakeholder questionnaire') for CYP who believed their mental health and wellbeing had improved during lockdown and parents who perceived improvement in their child. The stakeholder questionnaire asked for up to three reasons why participants thought their/their child's mental health and wellbeing had improved. We shared the stakeholder questionnaire with twelve parent networks across the country and on social media (Twitter and Facebook) and received approximately 400 responses (around three-quarters from parents and onequarter from CYP). Members of the study team (ES and NC) categorised all of the reasons provided into themes and discussed them with nine members of the Rethinking Education Action Group (https://rethinkingeducation.org.uk). This group was started by $\mathrm{NC}$, a parent support group facilitator and parent expert by experience, and is made up of parents and practitioners working to ensure that mental health and wellbeing are an intrinsic part of education. These group members clarified and expanded upon the suggestions and themes from the stakeholder questionnaire.

We then compared the list of suggestions from the stakeholder questionnaire to the list of variables available in the OxWell Survey data and looked for 'matches' across the two lists (see Supplementary Table 1). For example, one common 
suggestion from the stakeholder questionnaire was that CYP's mental health and wellbeing had improved during lockdown because there was less or no bullying. Variables available in the OxWell Survey that related to this suggestion included frequency of bullying in the past year, change in bullying over lockdown, safety at school, frequency of feeling left out, change in feeling left out during lockdown, and feelings about seeing classmates/peers when returning to school. We included all such 'matches' in our analyses, although it is important to note that not all suggestions provided had matching variables in the survey: for example, we were not able to explore a suggestion about not having to wear school uniform.

Supplementary Table 2 provides a full list of survey questions, their wordings, and response options used in this study, and full variable guides are available on the OxWell Study page on the Open Science Framework (OSF) website (https:// osf.io/sekhr/).

\section{Identifying students who reported better mental wellbeing during lockdown}

We measured perceived change in mental wellbeing with the question 'During lockdown, how happy have you been feeling in general (your mental well-being)?'. Students responded on a sliding scale of 0-100 with five labelled categories, 'Much worse', 'Slightly worse', 'The same', 'Slightly better', and 'Much better', anchored at scores 0, 25, 50, 75, and 100, respectively. We simplified the scale in this analysis by transforming it into groups of those doing 'worse' (scores 0-37.5 on the sliding scale), 'the same' (scores 37.6-62.5), or 'better' (scores 62.6-100) (N.B. categories are not evenly divided due to how the scale is presented in the survey; please see https:// osf.io/fpbt3/ for an example of the survey scales).

\section{Sociodemographic characteristics}

We included the following sociodemographic measures: gender (measured as male or female or boy or girl, depending on age group), key stage (referring to students' year in school), free school meal eligibility, immigration status (measured as student and both parents born in the UK; both parents born in the UK, student born elsewhere; student born in the UK, at least one parent born elsewhere; or student and at least one parent born elsewhere), and garden access (no access to a garden, having access to a garden but not using it, having access to a garden and using it sometimes, or having access to a garden and using it every day).

\section{Student experiences of schooling, home life, lifestyle factors, and relationships}

We also included the following measures in our analyses: school attendance during lockdown, perceptions of safety at school and at home, concern about school performance, academic support at school and at home, school task management, bullying, friend and family relationships, loneliness and exclusion, exercise, and sleep. We conceptually divided these measures into reference measures (those that asked students about their general experiences, e.g. 'How well do you get along with your friends?') and measures of change during lockdown (those that asked students how lockdown has changed their experiences, e.g. 'During lockdown, have you got along less well, the same or better with your friends?').

We further included measures of students' feelings about eight aspects related to returning to school after lockdown: seeing friends again, seeing other classmates/peers, schoolwork, attending lessons, being away from home, sports and exercise activities, other school/outside-school clubs, and travelling to and from school.

\section{Mental health \& wellbeing}

We measured mental wellbeing at the time of completing the survey using the Warwick-Edinburgh Mental Wellbeing Scale (WEMWBS) [24]. The scale has 14 positively-worded items with four response categories according to frequency (1-'none of the time', 2-'rarely', 3-'some of the time', 4-'often', 5- 'all of the time') that sum to a total score of 14-70, with higher scores indicating higher wellbeing. The WEMWBS has demonstrated good internal consistency $(\alpha=0.87)$ in young people aged 13-16 years [25]. In the OxWell Survey, the scale was slightly modified such that participants rated statements on a $0-100$ sliding scale with the same labels as the original scale. For adolescents in Years 8-13, we also measured mental illness using the (unmodified) 25-item version of the Revised Child Anxiety and Depression Scale (RCADS) [26]. All statements have four response categories according to frequency (0-'never', 1-'sometimes', 2-'often', 3- 'always'). Responses sum to a Total Anxiety and Depression score (0-75), as well as a Total Anxiety sub-score (0-45) and a Total Depression subscore (0-30), with higher scores indicating greater mental health difficulties. In this study, we used $t$ scores for the Total Anxiety and Depression score [27]. The RCADS-25 has demonstrated acceptable to excellent internal consistency (subscale range $\alpha=0.79$ to 0.94 ) in school-based samples and adequately discriminates between young people with and without mental health diagnoses [26].

\section{Analysis}

We described the aggregate characteristics of participating schools by means and standard deviations (SDs) for continuous variables, and absolute and relative frequencies for categorical variables. Similarly, we summarised students' 
sociodemographic characteristics and their answers to the questions about school, home, relationships, and lifestyle using the appropriate absolute and relative frequencies, medians, and interquartile ranges (IQRs).

For our main analysis, we grouped students into one of our derived three-group self-reported wellbeing categories of doing 'better', 'the same', or 'worse' and compared these groups by medians, IQRs, and absolute and relative frequencies. For the questions measuring students' feelings about returning to school after lockdown, we excluded students who reported physically attending school 'most days' or 'every day' during the lockdown. All analyses were conducted using $\mathrm{R}$ version 4.0.5 (using packages tidyverse, patchwork, and summarytools).

\section{Results}

22,336 students across 144 primary schools, 84 secondary schools, and 7 FECs accessed the survey (Table 1). Whilst it is not possible to calculate response rate due to uncertainty around the total number of students invited, some students will not have accessed the survey for reasons including (1) not being contacted/invited by their school, (2) being optedout by parents, (3) not reading the survey information, or (4) choosing not to participate (numbers per category are not available). Survey administrators further removed 4,731 responses $(21 \%)$ due to spending fewer than $10 \mathrm{~min}$ on the survey or providing unrealistic/inconsistent responses. Of the 17,605 remaining participants, 16,940 answered the question about change in mental wellbeing and were included in our final sample.

\section{Proportion of CYP who self-reported improvement in their mental wellbeing during lockdown}

One-third $(N=5616 ; 33.2 \%)$ of students reported that their mental wellbeing had improved during lockdown, compared with $N=5581(32.9 \%)$ who reported that it remained the same and $N=5743$ (33.9\%) who reported that it had deteriorated (Fig. 1). Supplementary Fig. 1 shows the association between self-reported change in mental wellbeing and (1) WEMWBS and (2) RCADS scores. WEMWBS scores indicated that those who reported improved mental wellbeing
Table 1 Aggregate characteristics of participating schools

\begin{tabular}{ll}
\hline Characteristics & \\
\hline School context & \\
Urbanicity $N(\%)$ & $54(23.7 \%)$ \\
Rural & $174(76.3 \%)$ \\
Urban & $7(2.9 \%)$ \\
Missing & \\
Area-level deprivation decile (IMD) N(\%) & $68(28.9 \%)$ \\
$1-5$ (most deprived) & $160(68.1 \%)$ \\
$6-10$ (least deprived) & $7(2.9 \%)$ \\
Missing & $10.1(7.4)$ \\
Characteristics of school community* & $67.8(25.6)$ \\
Percentage of pupils eligible for free school meals Mean (SD) & \\
Percentage of pupils who are White British Mean (SD) & \\
Operational features of the school & $142(60.4 \%)$ \\
Type of school N (\%) & $79(33.6 \%)$ \\
State-funded primary & $7(2.9 \%)$ \\
State-funded secondary & $7(2.9 \%)$ \\
Independent school & \\
Further Education College & \\
Mixed or single sex school N (\%) & $213(90.6 \%)$ \\
Mixed & $9(3.8 \%)$ \\
Female only & $6(2.5 \%)$ \\
Male only & $7(2.9 \%)$ \\
Missing & \\
\hline
\end{tabular}

*Data not available for independent/academy schools or FECs 
Fig. 1 (1) Self-reported change in mental wellbeing during lockdown; (2) Frequency of school attendance by selfreported change in mental wellbeing during lockdown

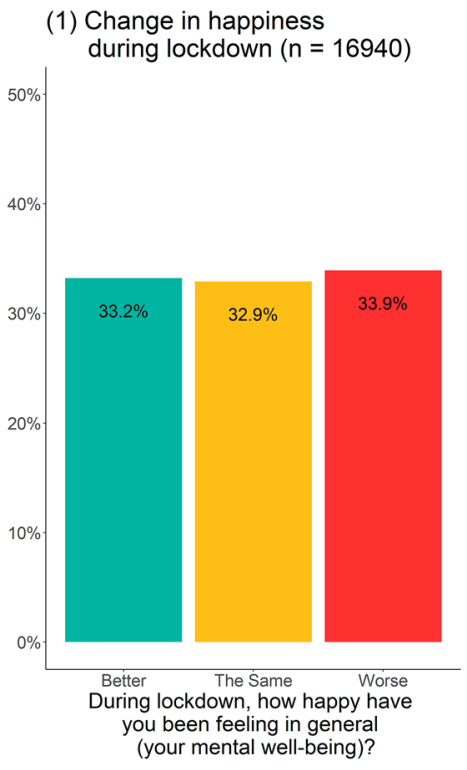

(2) Frequency of school attendance during lockdown by reported change in happiness $(n=16675)$

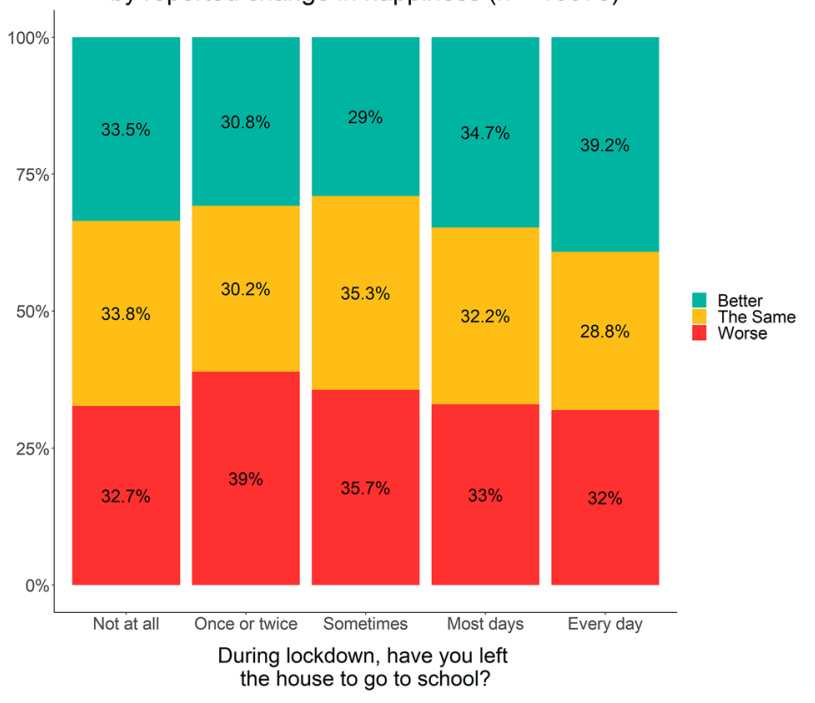

during lockdown also had higher WEMWBS scores (median 53.0, IQR: 48.0; 58.0) than their peers who reported a deterioration (median 40.0, IQR: 34.0; 47.0) or no change (median 51.0, IQR: 45.0; 56.0). Those who reported improvement had lower levels of depression and anxiety (RCADS median 42.7, IQR: 36.1 ; 52.9) than their peers who reported deterioration (median 58.8, IQR: 48.1; 71.3) but were similar to their peers who reported no change (median 42.5, IQR: $35.6 ; 51.8)$.

\section{Characteristics of CYP who self-reported improvement in their mental wellbeing during lockdown}

Table 2 overviews relationships between all variables of interest and self-reported change in mental wellbeing during lockdown.

\section{Sociodemographic characteristics}

Supplementary Fig. 2 shows responses by gender, key stage, free school meal eligibility, immigration status, and garden access. Sociodemographic characteristics were similar in the groups who reported improvement in their mental wellbeing and those who reported no change, whilst the group who reported deterioration in their wellbeing had proportionally more girls and older students.

\section{School factors}

In terms of school attendance, the highest proportions of students who reported improved mental wellbeing were amongst those who were in school every day $(39.2 \%)$, most days (34.7\%), or not at all (33.5\%) (Fig. 1). For the four reference variables studied (i.e. perceptions of safety at school, concern about school performance, and academic support at school and at home), those who reported improved mental wellbeing were largely similar to those who reported no change, and each of these groups reported more positive experiences than did the group who reported deterioration (Table 1).

In terms of self-reported changes during lockdown, the proportion of students who reported that they were managing their school tasks 'slightly' or 'much' better than before lockdown was higher for the group who reported improved mental wellbeing (42.6\%) than for the groups who reported no change $(23.1 \%)$ or deterioration (17.3\%) (Fig. 2).

\section{Home factors}

The proportion of students who reported that they felt 'safe' or 'very safe' at home was similar for those who reported improvement $(96.1 \%)$ and no change $(93.5 \%)$ in mental wellbeing and lower for those who reported deterioration $(84.3 \%)$.

\section{Relational factors}

For the six reference variables studied (i.e. past year experience of bullying, family relationships, friend relationships, feeling lonely, feeling left out, and concern about appearance), those who reported improved mental wellbeing were largely similar to those who reported no change, and each of these groups reported more positive experiences than did the group who reported deterioration (Table 1).

In terms of self-reported changes during lockdown, a higher proportion of those who reported improved mental wellbeing also reported improvements across all relational 
Table 2 Characteristics by self-reported change in mental wellbeing

\begin{tabular}{|c|c|c|c|c|}
\hline Variable & $\begin{array}{l}\text { Missing data } \\
(\%)\end{array}$ & Worse $N(\%)$ & The same $N(\%)$ & Better $N(\%)$ \\
\hline \multicolumn{5}{|l|}{ Sociodemographic factors } \\
\hline Gender & 0.6 & & & \\
\hline Male & & $1836(32.2)$ & $2361(42.5)$ & $2400(43.0)$ \\
\hline Female & & $3861(67.8)$ & $3199(57.5)$ & $3185(57.0)$ \\
\hline Ages (key stage $(K S))$ & 0 & & & \\
\hline Ages 8-11 (KS2) & & $942(16.4)$ & $1209(21.7)$ & $1276(22.7)$ \\
\hline Ages 12-14 (KS3) & & $2643(46.0)$ & $2983(53.4)$ & $2874(51.2)$ \\
\hline Ages 15-16 (KS4) & & $1293(22.5)$ & $919(16.5)$ & $1015(18.1)$ \\
\hline Ages 17-18 (KS5) & & $865(15.1)$ & $470(8.4)$ & $451(8.0)$ \\
\hline Free school meal eligibility & 3.7 & & & \\
\hline No & & $4127(73.9)$ & $3972(74.1)$ & 3989 (73.6) \\
\hline Yes & & $480(8.6)$ & 407 (7.6) & $504(9.3)$ \\
\hline Don't know & & $975(17.5)$ & $983(18.3)$ & $928(17.1)$ \\
\hline Immigration status & 3.2 & & & \\
\hline Student \& parents all UK-born & & $3592(64.3)$ & $3343(61.6)$ & $3171(58.5)$ \\
\hline Student UK-born with at least one parent born elsewhere & & $1406(25.2)$ & $1451(26.8)$ & $1536(28.3)$ \\
\hline Both parents UK-born but not student & & $61(1.1)$ & $65(1.2)$ & $59(1.1)$ \\
\hline Student and at least one parent born elsewhere & & $531(9.5)$ & $564(10.4)$ & $657(12.1)$ \\
\hline Garden access & 0.6 & & & \\
\hline Yes, use every day & & $2178(38.1)$ & $2612(47.1)$ & $2724(48.8)$ \\
\hline Yes, sometimes use & & $2905(50.8)$ & $2513(45.3)$ & $2387(42.8)$ \\
\hline Yes, but do not use & & $422(7.4)$ & $238(4.3)$ & $268(4.8)$ \\
\hline No & & $213(3.7)$ & $183(3.3)$ & $204(3.7)$ \\
\hline \multicolumn{5}{|l|}{ School factors } \\
\hline School attendance & 1.6 & & & \\
\hline Not at all & & $3770(66.9)$ & $3890(70.5)$ & $3865(70.0)$ \\
\hline Once or twice & & $939(16.7)$ & $728(13.2)$ & $742(13.4)$ \\
\hline Sometimes & & $417(7.4)$ & $413(7.5)$ & $339(6.1)$ \\
\hline Most days & & $328(5.8)$ & $320(5.8)$ & $345(6.3)$ \\
\hline Every day & & $185(3.3)$ & $167(3.0)$ & $227(4.1)$ \\
\hline Safety at school & 2.1 & & & \\
\hline Very safe & & $1530(27.2)$ & $2067(37.5)$ & $2147(38.9)$ \\
\hline Safe & & $2568(45.7)$ & $2513(45.5)$ & $2390(43.3)$ \\
\hline Neither safe nor unsafe & & $1115(19.8)$ & $804(14.6)$ & $785(14.2)$ \\
\hline Unsafe & & $332(5.9)$ & $99(1.8)$ & $155(2.8)$ \\
\hline Very unsafe & & $79(1.4)$ & $35(0.6)$ & $40(0.7)$ \\
\hline Concern about school performance* & 2.9 & & & \\
\hline Not at all worried & & $122(3.2)$ & $294(9.5)$ & $303(9.7)$ \\
\hline Not very worried & & $408(10.8)$ & $808(26.2)$ & $764(24.4)$ \\
\hline Quite worried & & $601(15.9)$ & $792(25.6)$ & $729(23.3)$ \\
\hline Worried & & $1457(38.5)$ & $873(28.3)$ & $901(28.8)$ \\
\hline Extremely worried & & $1198(31.6)$ & $322(10.4)$ & $436(13.9)$ \\
\hline Academic support at home & 3.8 & & & \\
\hline All of the help I need & & $950(17.1)$ & $1682(30.9)$ & $1829(33.7)$ \\
\hline Most of the help I need & & $1414(25.5)$ & $1665(30.6)$ & $1811(33.3)$ \\
\hline Just about enough help & & $1559(28.1)$ & $1480(27.2)$ & $1186(21.8)$ \\
\hline Not enough help & & $806(14.5)$ & $337(6.2)$ & $315(5.8)$ \\
\hline No help at all & & $811(14.6)$ & $277(5.1)$ & $290(5.3)$ \\
\hline
\end{tabular}


Table 2 (continued)

\begin{tabular}{|c|c|c|c|c|}
\hline Variable & $\begin{array}{l}\text { Missing data } \\
(\%)\end{array}$ & Worse $N(\%)$ & The same $N(\%)$ & Better $N(\%)$ \\
\hline Academic support at school & 3.9 & & & \\
\hline All of the help I need & & 739 (13.4) & $1359(24.9)$ & $1398(25.8)$ \\
\hline Most of the help I need & & $1875(33.9)$ & $2042(37.5)$ & $2138(39.4)$ \\
\hline Just about enough help & & $1644(29.7)$ & $1601(29.4)$ & $1309(24.1)$ \\
\hline Not enough help & & $1076(19.5)$ & $386(7.1)$ & $481(8.9)$ \\
\hline No help at all & & $196(3.5)$ & $62(1.1)$ & $101(1.9)$ \\
\hline School task management (change during lockdown) & 4.2 & & & \\
\hline Much better & & $281(5.0)$ & $373(6.9)$ & $930(17.3)$ \\
\hline Slightly better & & $688(12.3)$ & $875(16.2)$ & $1359(25.3)$ \\
\hline The same & & 1205 (21.6) & $2375(43.9)$ & $1601(29.8)$ \\
\hline Slightly worse & & $2173(38.9)$ & $1500(27.7)$ & $1196(22.2)$ \\
\hline Much worse & & $1243(22.2)$ & $286(5.3)$ & $292(5.4)$ \\
\hline \multicolumn{5}{|l|}{ Home factors } \\
\hline Safety at home & 1.1 & & & \\
\hline Very safe & & $2914(51.4)$ & $3777(68.2)$ & $4230(75.8)$ \\
\hline Safe & & $1865(32.9)$ & $1400(25.3)$ & $1135(20.3)$ \\
\hline Neither safe nor unsafe & & $606(10.7)$ & $299(5.4)$ & $169(3.0)$ \\
\hline Unsafe & & $237(4.2)$ & $50(0.9)$ & $37(0.7)$ \\
\hline Very unsafe & & $45(0.8)$ & $12(0.2)$ & $10(0.2)$ \\
\hline \multicolumn{5}{|l|}{ Relational factors } \\
\hline Bullying (past year) & 1.0 & & & \\
\hline Never & & $4552(79.9)$ & $4887(88.2)$ & $4461(80.1)$ \\
\hline $2-3$ times a month & & $660(11.6)$ & $414(7.5)$ & $635(11.4)$ \\
\hline Weekly & & $164(2.9)$ & $106(1.9)$ & $166(3.0)$ \\
\hline Most days & & $254(4.5)$ & $97(1.8)$ & $237(4.3)$ \\
\hline Every day & & $70(1.2)$ & $37(0.7)$ & $71(1.3)$ \\
\hline $\begin{array}{l}\text { Bullying (change during lockdown) for those bullied in the past } \\
\text { year }\end{array}$ & 1.7 & & & \\
\hline Much less & & $674(59.7)$ & $414(64.6)$ & $878(80.4)$ \\
\hline Slightly less & & $236(20.9)$ & $120(18.7)$ & $131(12.0)$ \\
\hline The same amount & & $79(7.0)$ & $50(7.8)$ & $25(2.3)$ \\
\hline Slightly more & & $91(8.1)$ & $42(6.6)$ & $40(3.7)$ \\
\hline Much more & & $49(4.3)$ & $15(2.3)$ & $18(1.6)$ \\
\hline Friend relationships (reference) & 1.5 & & & \\
\hline Very well or well & & $3622(63.8)$ & $4068(73.8)$ & $4006(72.6)$ \\
\hline Most of the time well & & $1861(32.8)$ & $1394(25.3)$ & $1422(25.8)$ \\
\hline Not well or not at all well & & $190(3.3)$ & $52(0.9)$ & $90(1.6)$ \\
\hline Friend relationships (change during lockdown) & 7.7 & & & \\
\hline Much better & & $319(5.9)$ & $251(4.7)$ & $674(12.9)$ \\
\hline Better & & $1121(20.9)$ & $1149(21.7)$ & $1468(28.1)$ \\
\hline The same & & $2669(49.8)$ & $3334(62.9)$ & $2433(46.6)$ \\
\hline Less & & $996(18.6)$ & $500(9.4)$ & $543(10.4)$ \\
\hline Much less & & $258(4.8)$ & $70(1.3)$ & $106(2.0)$ \\
\hline Family relationships (reference) & 0.9 & & & \\
\hline Very well or well & & $1741(30.5)$ & $2723(49.1)$ & $3158(56.7)$ \\
\hline Most of the time well & & $3423(60.0)$ & $2701(48.7)$ & $2299(41.3)$ \\
\hline Not well or not at all well & & $540(9.5)$ & $120(2.2)$ & $112(2.0)$ \\
\hline
\end{tabular}


Table 2 (continued)

\begin{tabular}{|c|c|c|c|c|}
\hline Variable & $\begin{array}{l}\text { Missing data } \\
(\%)\end{array}$ & Worse $N(\%)$ & The same $N(\%)$ & Better $N(\%)$ \\
\hline Family relationships (change during lockdown) & 6.4 & & & \\
\hline Much better & & $178(3.3)$ & $212(4.0)$ & $825(15.5)$ \\
\hline Better & & $988(18.1)$ & $1178(22.1)$ & $1969(37.0)$ \\
\hline The same & & $2271(41.7)$ & $3220(60.4)$ & $2039(38.3)$ \\
\hline Less & & $1652(30.3)$ & $665(12.5)$ & $445(8.4)$ \\
\hline Much less & & $361(6.6)$ & $57(1.1)$ & $47(0.9)$ \\
\hline Feeling left out (reference) & 1.8 & & & \\
\hline Never & & $1609(28.4)$ & $3125(56.8)$ & $3042(55.1)$ \\
\hline Sometimes & & $2881(50.9)$ & $2048(37.2)$ & $2087(37.8)$ \\
\hline Often & & $1167(20.6)$ & $329(6.0)$ & $390(7.1)$ \\
\hline Feeling left out (change during lockdown) & 9.3 & & & \\
\hline Much less & & $486(9.1)$ & $567(10.9)$ & $1273(24.7)$ \\
\hline Slightly less & & $1193(22.4)$ & $1066(20.6)$ & $1327(25.8)$ \\
\hline The same amount & & $2062(38.7)$ & $2948(56.9)$ & $1884(36.6)$ \\
\hline Slightly more & & $1257(23.6)$ & $542(10.5)$ & $564(10.9)$ \\
\hline Much more & & $325(6.1)$ & $57(1.1)$ & $103(2.0)$ \\
\hline Loneliness (reference) & 1.6 & & & \\
\hline Never & & $1295(22.8)$ & $3349(61.0)$ & $3391(61.3)$ \\
\hline Sometimes & & $2680(47.2)$ & $1750(31.9)$ & $1784(32.2)$ \\
\hline Often & & $1702(30.0)$ & $393(7.2)$ & $360(6.5)$ \\
\hline Loneliness (change during lockdown) & 8.0 & & & \\
\hline Much less & & $315(5.7)$ & $485(9.3)$ & $1226(23.7)$ \\
\hline Slightly less & & 643 (11.7) & $734(14.1)$ & $1082(21.0)$ \\
\hline The same amount & & $1342(24.4)$ & $2874(55.2)$ & $1789(34.7)$ \\
\hline Slightly more & & $2315(42.2)$ & $974(18.7)$ & $936(18.1)$ \\
\hline Much more & & $877(16.0)$ & $143(2.7)$ & $130(2.5)$ \\
\hline Concern about appearance* & 2.6 & & & \\
\hline Not at all worried & & $276(7.3)$ & $605(19.5)$ & $631(20.1)$ \\
\hline Not very worried & & $641(16.9)$ & $984(31.7)$ & $904(28.8)$ \\
\hline Quite worried & & $645(17.0)$ & $671(21.6)$ & $605(19.2)$ \\
\hline Worried & & $1163(30.7)$ & $574(18.5)$ & $705(22.4)$ \\
\hline Extremely worried & & $1069(28.2)$ & $275(8.8)$ & $298(9.5)$ \\
\hline \multicolumn{5}{|l|}{ Lifestyle factors } \\
\hline Exercise (left house during lockdown) & 5.1 & & & \\
\hline Every day & & $985(18.0)$ & $1062(19.8)$ & $1238(23.1)$ \\
\hline Most days & & $2214(40.5)$ & $2459(45.8)$ & $2454(45.9)$ \\
\hline Sometimes & & $1218(22.3)$ & $1177(21.9)$ & $931(17.4)$ \\
\hline Once or twice & & $758(13.9)$ & $495(9.2)$ & $511(9.5)$ \\
\hline Not at all & & $287(5.3)$ & $178(3.3)$ & $217(4.1)$ \\
\hline Exercise (change during lockdown) & 4.5 & & & \\
\hline Much more & & $496(9.0)$ & $475(8.8)$ & $861(16.0)$ \\
\hline Slightly more & & $1126(20.4)$ & $1197(22.2)$ & $1514(28.2)$ \\
\hline The same amount & & $533(9.6)$ & 964 (17.9) & $721(13.4)$ \\
\hline Slightly less & & $2091(37.8)$ & $2106(39.1)$ & $1711(31.8)$ \\
\hline Much less & & $1281(23.2)$ & $650(12.1)$ & 567 (10.6) \\
\hline
\end{tabular}


Table 2 (continued)

\begin{tabular}{|c|c|c|c|c|}
\hline Variable & $\begin{array}{l}\text { Missing data } \\
(\%)\end{array}$ & Worse $N(\%)$ & The same $N(\%)$ & Better $N(\%)$ \\
\hline Sleep (change during lockdown) & 9.6 & & & \\
\hline Much more & & $224(4.1)$ & $332(6.6)$ & $869(17.1)$ \\
\hline Slightly more & & $816(15.1)$ & $1172(23.3)$ & $1600(31.5)$ \\
\hline The same amount & & 1005 (18.6) & $2012(40.0)$ & $1387(27.3)$ \\
\hline Slightly less & & $2316(42.8)$ & $1292(25.7)$ & $1022(20.1)$ \\
\hline Much less & & $1052(19.4)$ & $223(4.4)$ & $205(4.0)$ \\
\hline
\end{tabular}

*Not asked of primary school pupils

Fig. 2 Self-reported changes in mental wellbeing and lifestyle and school factors
Reported change for those doing "Better", "The Same", and "Worse" during lockdown by:

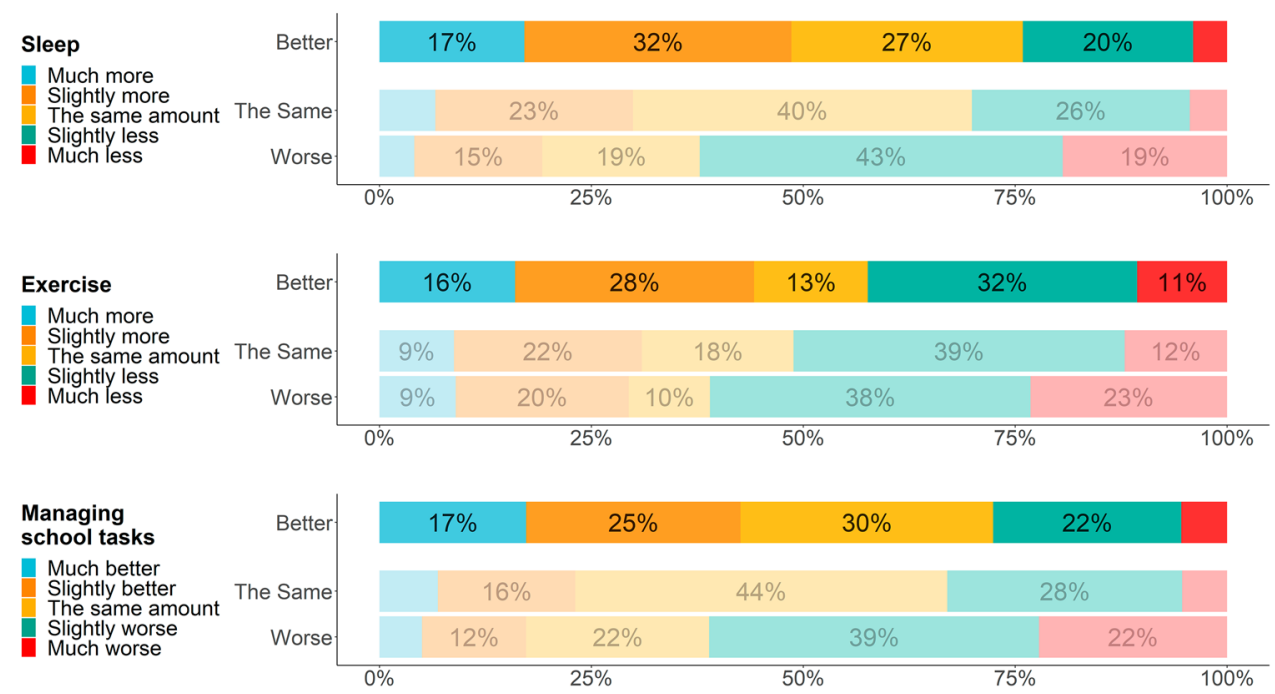

factors studied (Fig. 3). The proportion of students who reported that they were getting along with household members 'better' or 'much better' than before lockdown was higher for the group who reported improved mental wellbeing $(52.5 \%)$ than for the groups who reported no change (26.1\%) or deterioration $(21.4 \%)$, with a similar pattern for getting along with friends $(41.0 \%, 26.4 \%$, and $26.8 \%$ of those who reported improvement, no change, or deterioration, respectively). Feeling less left out or lonely during lockdown was also more common in this group: of those who reported improved mental wellbeing, $44.7 \%$ said they were 'slightly' or 'much' less lonely than before lockdown, compared with $23.4 \%$ and $17.4 \%$ of those who reported no change and deterioration, respectively. Furthermore, $50.5 \%$ of those who reported improved mental wellbeing reported feeling 'slightly' or 'much' less left out, compared with $31.5 \%$ of those who reported no change and $31.5 \%$ of those who reported deterioration. Finally, whilst all groups reported reduced bullying during lockdown, the proportion that reported that they were bullied 'slightly' or 'much' less than before lockdown was higher for those who reported improved wellbeing $(92.4 \%)$ than for those who reported no change $(83.3 \%)$ or deterioration $(80.6 \%)$.

\section{Lifestyle factors}

The proportion of students who reported that they left their house to exercise 'most days' or 'every day' was similar for those who reported improvement (69.0\%) or no change $(65.6 \%)$ in mental wellbeing and lower for those who reported deterioration $(58.5 \%)$. In terms of self-reported changes during lockdown, the proportion of students who reported that they were exercising 'much' or 'slightly' more than before lockdown was higher for the group who reported improved mental wellbeing $(44.2 \%)$ than for the groups who reported no change $(31.0 \%)$ or deterioration (29.4\%). Similarly, $48.6 \%$ of those who reported improved mental wellbeing reported sleeping 'slightly' or 'much' more, compared with $29.9 \%$ of those who reported no change and $19.2 \%$ of those who reported deterioration. 
Fig. 3 Self-reported changes in mental wellbeing and relational factors
Reported change for those doing "Better", "The Same", and "Worse" during lockdown by:

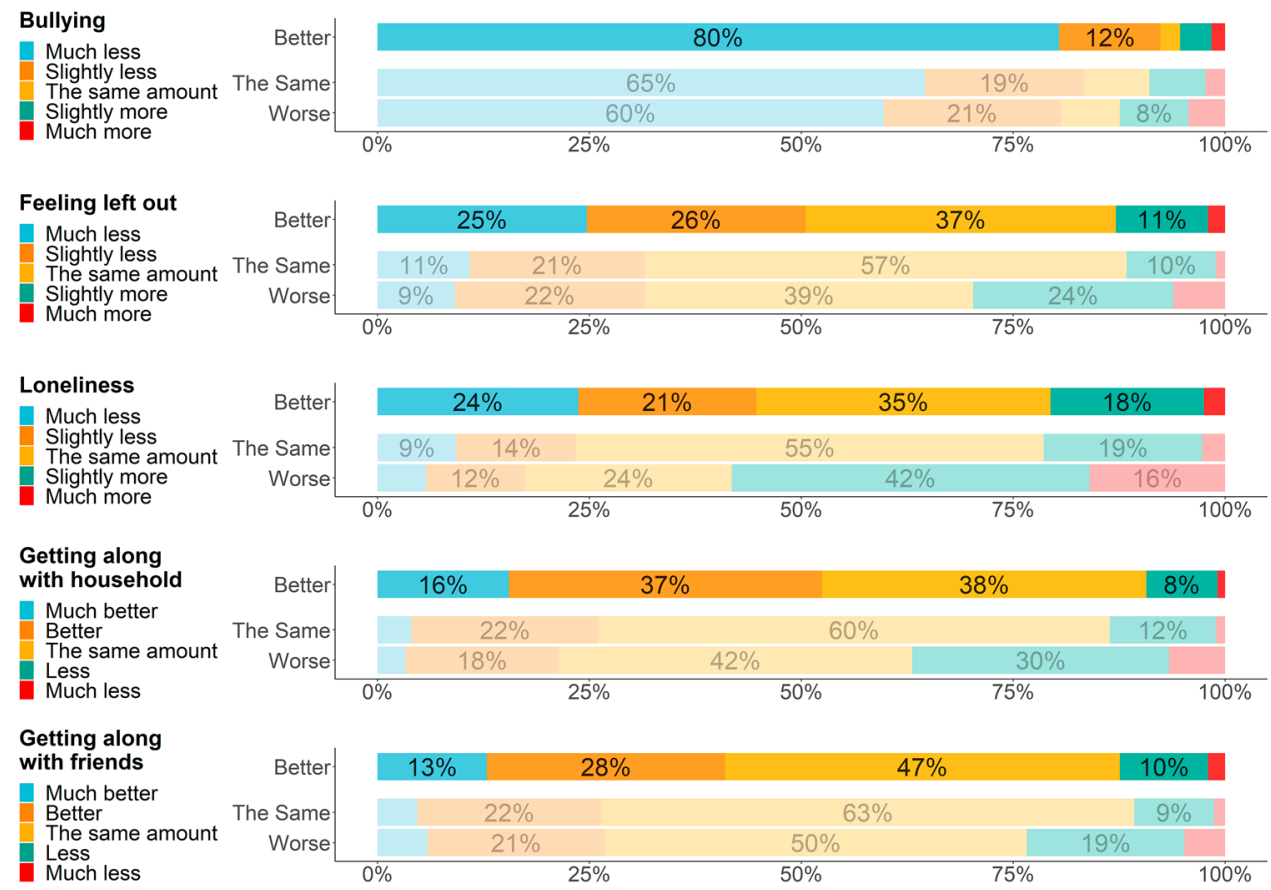

Thinking about going back to school/college when lockdown ends, how do you feel about the following?
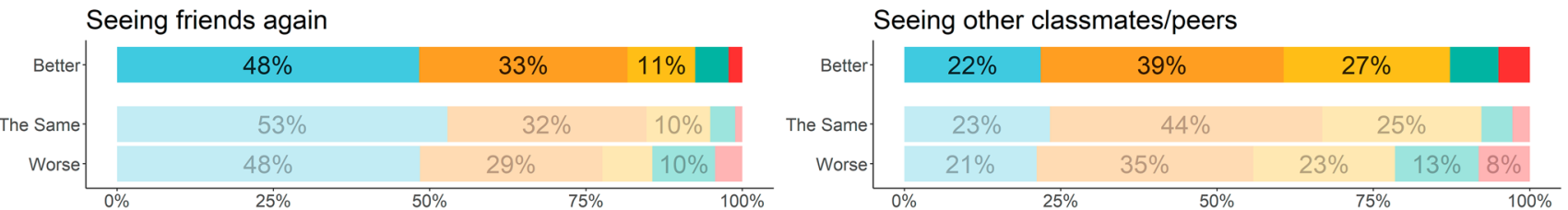

School/college work

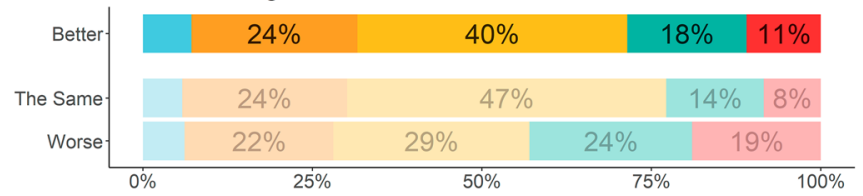

Being away from home

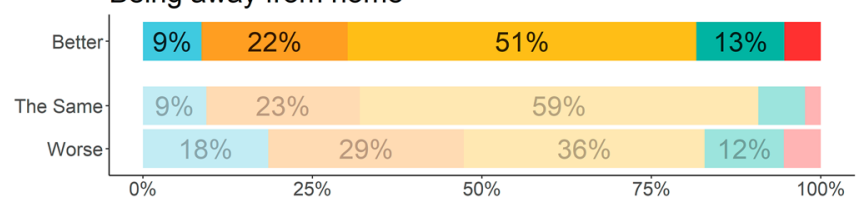

Other school and/or outside-school clubs
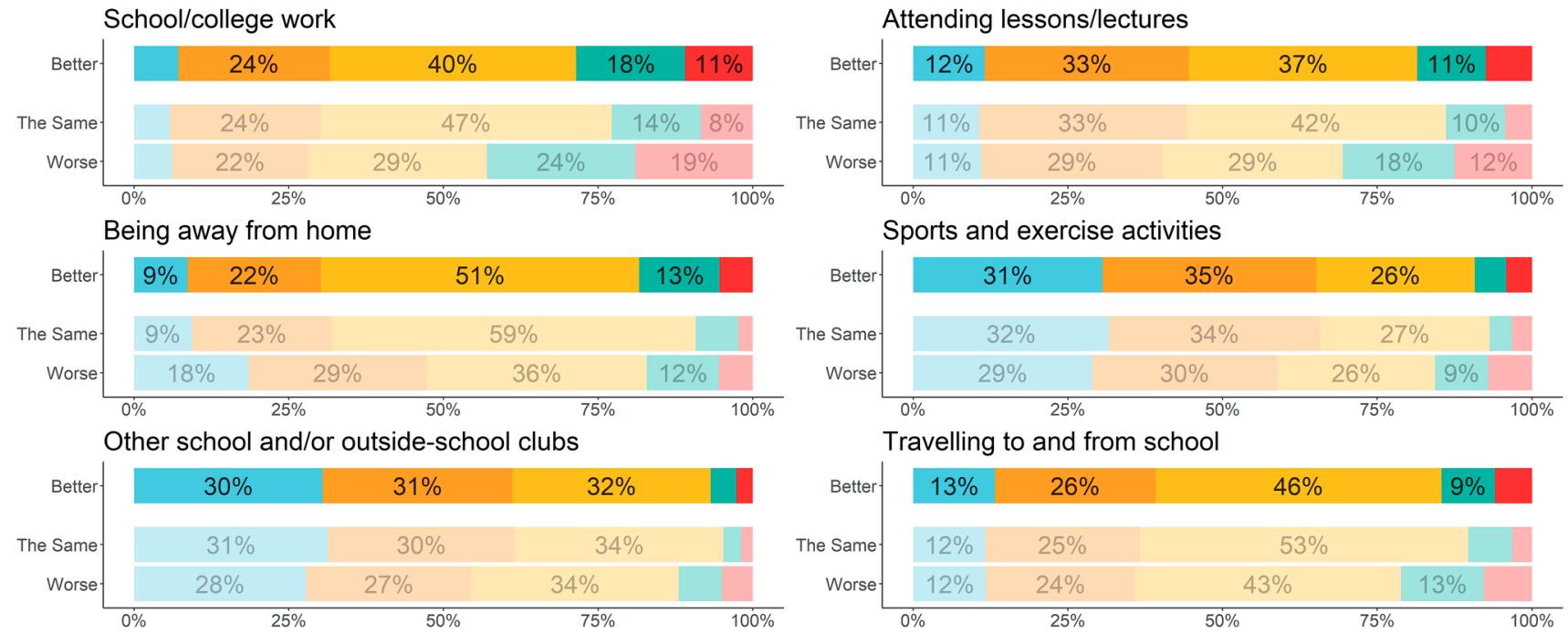

Sports and exercise activities

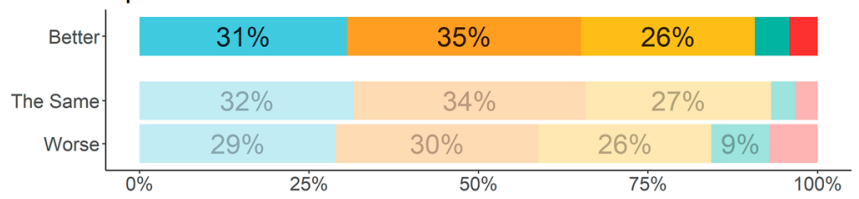

Travelling to and from school

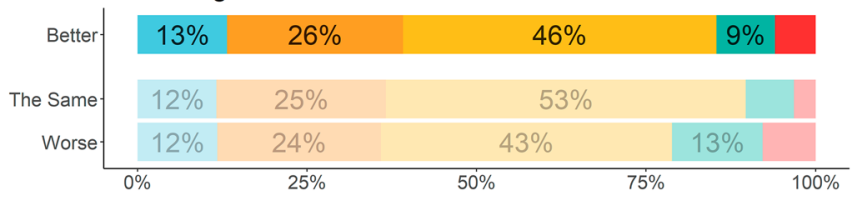

Can't wait $\square$ Looking forward to it $\square$ Neutral $\square$ Slightly worried $\square$ Dreading it

Fig. 4 Self-reported changes in mental wellbeing and feelings about returning to school 


\section{Feelings about returning to school after lockdown}

Differences in terms of feelings about returning to school were generally not as large as for other questions (Fig. 4; Supplementary Table 3). Excluding concerns about being away from home, the trend across all eight aspects was that the proportion 'slightly worried' about or 'dreading' the different aspects of school return was highest for those who reported deterioration in mental wellbeing, followed by those who reported improvement, and finally those who reported no change. Whilst students were generally positive or neutral about school return, aspects that the greatest number of students were concerned about were schoolwork (43.0\% of students who reported deterioration, $28.6 \%$ of those who reported improvement, and $22.8 \%$ of those who reported no change), attending lessons $(30.6 \%, 18.6 \%$, and $13.9 \%$, respectively), being away from home $(17.2 \%, 18.4 \%$, and $9.3 \%$, respectively), and travelling to and from school $(21.2 \%, 14.6 \%$, and $10.3 \%$, respectively).

\section{Discussion}

This large school-based study showed that one-third of students reported an improvement in their mental wellbeing during the first UK Covid-19 lockdown, representing a similar proportion to those who reported no change or deterioration to their wellbeing. For many of the reference variables studied (i.e. those that asked about general experiences versus lockdown-specific changes), students who reported improvement were quite similar to their peers who reported no change, and both groups fared better than those who reported deterioration. However, for the variables that measured self-reported changes during lockdown, CYP who reported improved mental wellbeing were more likely than their peers to report improvement across the full range of school, relational, and lifestyle factors studied.

This study adds to a growing evidence base that suggests that the impact of lockdown is dependent on a number of factors (e.g. gender, pre-pandemic mental health, social relationships, school connectedness, experience of online learning, family composition, and family financial situation $[4,5,7-9,11])$ and that there are many CYP who report experiencing better mental health and wellbeing during this time $[8,9,11]$. Whilst our estimate that one in three CYP experienced improved mental wellbeing during lockdown is higher than estimates from other studies, it is difficult to directly compare due to different sampling techniques and outcome measures, as well as variability in the nature of and response to the pandemic across geographical and chronological contexts. One of the most similar studies in terms of pandemic context is the English National Survey [1], which was conducted during the same timeframe as our survey. The estimate from this study, that $27 \%$ of $11-16$-year-olds said that lockdown had made their lives better, is fairly comparable to our own. A Canadian study conducted around the same time (during 'national emergency measures' including school closures) had a slightly lower estimate, with around $20 \%$ of CYP experiencing an improvement in at least one domain of mental health.

The patterns in changes in mental wellbeing by school attendance during lockdown are interesting. Various aspects of the school environment, including bullying [28, 29], academic stress [30-32], and poor relationships with teachers [33], are linked to poor mental health. It would, therefore, be reasonable to expect that being away from the school environment could be beneficial for certain students [18]. However, we found that those attending school 'most days' or 'every day' (though they made up a small percentage of the total sample) had a higher proportion of students who reported improved mental wellbeing compared with those attending irregularly. Interpreting these findings requires nuance, however, and our findings cannot determine whether school attendance was driving changes in mental wellbeing. As described in the Methods section, at the time of the survey, only certain students were eligible for in-school provision. Additionally, an analysis of secondary school students from the OxWell Survey demonstrated that contextual and background factors, such as previous access to mental health support, may explain the relationship between school attendance and change in mental wellbeing [19]. For those in school, the experience was likely substantially different, influenced by the demographic and environmental school context. Some would have had their same teachers in smaller class sizes whilst others might have experienced blended lessons with other students whom they might never have learned with before. Some would have had none of their friendship group with them at school, whilst others might have been able to be with friends and/or away from more difficult interpersonal relationships. Discussions with stakeholders (including CYP, parents, and teachers) suggest that this altered provision may well have been a positive experience, with potential for greater attention from teachers, more tailored learning, and increased focus on wellbeing.

This study also highlights the importance of relationships. The potential for increased social isolation during the pandemic is concerning, particularly for young people, for whom peer interactions are especially important [34, 35]. Widnall and colleagues [8] reported during the first UK lockdown that $42 \%$ of girls and $27 \%$ of boys worried about the impact of lockdown on friendships. Concerns about friendships were also common in young people's qualitative accounts of the pandemic, with many citing disruptions to their social networks and feelings of loneliness and isolation $[12,13,15,16]$. Yet, nearly half of those who reported improved mental wellbeing in our sample reported feeling 
less left out and lonely and having better relationships with friends and family. There are a number of reasons why this may be. As Orben and colleagues [34] have suggested, most CYP have access to digital forms of social interaction that can mitigate the negative effects of reduced face-to-face contact. This is also reflected in Widnall and colleagues' [8] finding that peer connectedness remained largely stable during the pandemic. With many parents and carers at home, there was also potential for improved family relationships, a fact empirically demonstrated in Penner and colleagues' [9] finding that better family functioning was associated with better mental health during the first period of 'stay at home' orders and school closures in the United States.

One specific aspect of peer relationships that changed during the pandemic was bullying. To our knowledge, this is the first study to quantify the relationship between change in bullying and change in mental wellbeing during lockdown. At the start of the pandemic, some experts were worried that bullying, and cyberbullying in particular, could increase $[32,36]$. Others believed that CYP who experience bullying at school would fare better during the lockdown due to increased control over social interactions and greater ability to focus on academic study [18]. In terms of empirical evidence, Silk and colleagues [15] found that around half of the nearly 100 adolescent girls in their diary-based study listed the ability to avoid unwanted interactions with classmates as a positive impact of the pandemic. We found that most CYP who had been bullied in the past year reported that the bullying had reduced, and given the well-established links between bullying and mental health [37], it was unsurprising that reductions were most prevalent amongst those who reported improved mental wellbeing.

For approximately half of the CYP who reported improved mental wellbeing, lockdown was associated with improvements in sleep and exercise. Sleep is crucial for CYP's mental health and wellbeing [38], and it was not initially clear how the pandemic would affect sleep [32]. In their study of sleep during Singapore's national lockdown in April-June 2020 (which included school closures), Lim and colleagues [39] found that, on average, CYP got more sleep during this time, and Silk and colleagues [15] found that $87 \%$ of the girls in their study reported increased sleep as a positive impact of the pandemic. These findings support discussions as to whether typical school start times are optimal for CYP's sleep. In examining the role of exercise, a more complicated picture emerged. Whilst CYP were encouraged to continue exercising during the pandemic, lockdown restrictions often limited opportunities for outdoor and group exercise. Interestingly, in Silk and colleagues' [15] diary study, three-quarters of the girls reported having more time to exercise or go outdoors. In our survey, whilst more CYP who reported improved mental wellbeing reported doing more exercise, there was a bimodal distribution, with as many reporting doing more exercise as doing less.

This study also highlighted the aspects of school return that students most looked forward to and those that they worried about most. The most anticipated aspect of school return was seeing friends again, whilst other positive aspects included seeing classmates and peers and participating in sports and other activities, all of which highlight the central role of peer interaction in CYP's lives [34]. This finding resonates with a key theme from Fisher and colleagues' [12] qualitative interviews, namely that the majority of young people were looking forward to going back to school and seeing their friends after the first UK lockdown. Conversely, the aspects causing the most concern were primarily related to school systems, including lessons and schoolwork. This reflects findings from other studies that school and academic concerns including disrupted learning and uncertainty about upcoming examinations were common amongst CYP during lockdown $[8,12,15,16]$. For some CYP, lockdown will have meant a reduction in academic stress or a more flexible learning system that better suited their needs, each of which may contribute to improved mental health and wellbeing.

\section{Limitations}

We acknowledge six main limitations. First, whilst our sample is large and diverse, it may not be representative of the general UK population, and we did not conduct a weighted analysis to account for potential differences between our sample and the population. For example, participants were from the south of England, which is relatively affluent compared with other areas of the country. Additionally, most students had to complete the survey from home, which could exclude students without the necessary resources (a computer, internet) or other vulnerable students (e.g. those who do not have a safe home environment). Second, due to the repeated cross-sectional design of the survey, we do not have (individually linkable) pre-pandemic data to indicate objective change in mental wellbeing or in any of our other variables of interest. Third, our validated measure of wellbeing (the WEMWBS) was slightly modified in the OxWell survey to be answered on a sliding scale, which potentially could have altered its psychometric properties. Fourth, there are several relevant variables missing from our data. Due to the ethical requirements associated with obtaining opt-out consent, we were not able to collect information on students' ethnicity or include gender options beyond male/female. In the stakeholder questionnaire, parents and CYP also identified a number of potentially relevant variables that were not available in the OxWell survey data, including factors related to school systems (e.g. flexible learning, autonomy over school work, class sizes) and neurodiversity (e.g. autism, sensory needs). These are key variables that warrant further 
study, ideally using mixed methods that include qualitative interviews. Fifth, we collected data only during the first lockdown; anecdotal experience from CYP, families, and school staff members indicates that this lockdown was qualitatively different from the others, but we were not able to explore this. Finally, we primarily aimed to explore the characteristics of those reporting better wellbeing during lockdown and describe their feelings and behaviours rather than model the relative contribution of these factors to their reported wellbeing. There are likely to be complex interrelationships between the factors we measured and whether a pupil had improved wellbeing during lockdown, which would benefit from further exploration.

\section{Lessons learned and consequences for the future}

This study provides insight into individual and environmental factors that may support CYP to thrive in the context of school disruption and adversity. First, considering educational differences, there were increased opportunities during lockdown for flexible and tailored teaching that encouraged different styles of learning and student autonomy over schedule and schoolwork $[12,14,15,18]$. For those in school, smaller class sizes and more focused attention from teachers might have had a positive impact to wellbeing, whilst later wake times $[32,39]$ and more freedom during the school day $[15,18]$ might have benefitted students at home. For some, there was more focus on sport, play, and the creative arts $[12,14,15]$, which may have contributed to wellbeing, although it is likely that this was more accessible for only a minority of students. For certain students, there may also have been fewer 'typical school day' distractions (e.g. negative comparisons with other students, school-based anxiety, sensory challenges, concerns about disciplinary action, and uniform requirements $[8,18])$. Finally, there was a greater emphasis in both schools and wider society on maintaining wellbeing [40, 41].

Second, interpersonal relationships during the pandemic were altered. Some CYP experienced improvements in relationships with family and friends [9, 14-16], often facilitated by social media and other digital platforms [8, 12, 16, 42]. CYP who were in school during this time may have had the opportunity to make new friendships, whilst others experienced a respite from negative relationships [15, 18, 19]. All groups in this study reported less bullying during lockdown, potentially reflecting better opportunities to control their exposures to peers who might have been targeting them in the classroom or during unstructured times in the school day (e.g. on the journey to/from school or in break times).

Taken together, these findings challenge the dominant narrative that the pandemic and accompanying lockdown measures have had overwhelmingly adverse effects on the lives of CYP. Determining the reasons why some CYP felt they fared better during lockdown and considering how these beneficial experiences can be maintained beyond the pandemic might provide valuable insights into mental health and wellbeing not only for these students, but for the millions of young people being educated during the Covid-19 pandemic. Based on our findings, a dual emphasis at school on both achievement and building interpersonal relationships seems essential. Furthermore, additional flexibility on certain aspects of school structure and expectations might better support CYP's mental health and wellbeing. Importantly, the responsibility to conceptualise and implement any needed changes cannot fall only on individual schools or educators, but instead must be part of a systemic shift including all those working with school-aged CYP and their families.

In summary, CYP have had diverse experiences of the pandemic, influenced by a multitude of interacting individual-, family-, and community-level risk and protective factors. The negative impacts to the lives of many affected by illness, socioeconomic stressors, and disruptions to family and community life cannot be ignored. However, some CYP have experienced positive changes during the pandemic, which necessitate further examination, exploration, and reflection.

Supplementary Information The online version contains supplementary material available at https://doi.org/10.1007/s00787-021-01934-z.

Acknowledgements The authors wish to acknowledge the important contributions of the parents and young people who took part in the stakeholder questionnaire, the Rethinking Education Action Group (https://rethinkingeducation.org.uk/), and the Cambridge Mental Health in Schools Advisory Group for their input into the design and interpretation of the analyses. The investigators acknowledge the philanthropic support of the donors to the University of Oxford's COVID19 Research Response Fund. They would like to thank all the students who took part in the OxWell Student Survey and the many staff at participating schools and colleagues in local authorities and clinical commissioning groups for the effort they put into promoting and conducting the survey at a hectic time. Finally, they would like to thank Pauline Foster and Elaine Purse at Foster and Brown Research Limited who provide the infrastructure for the OxWell survey.

Funding ES is funded by a Gates Cambridge Scholarship (Grant Number: OPP1144). SP is funded by a National Institute for Health Research (NIHR) Post-Doctoral Fellowship award (Grant Number PDF-2017-10-029) and The Westminster Foundation. NC is supported by funding from the UK Research and Innovation (UKRI) Emerging Minds Network. KLM is funded by the NIHR Oxford Health Biomedical Research Centre (BRC-1215-20005). PBJ is supported by the NIHR Applied Research Collaboration East of England. MF was supported by funding from the NIHR Applied Research Collaboration Oxford and Thames Valley at Oxford Health NHS Foundation Trust. The OxWell Student Survey is supported by the NIHR Oxford Health Biomedical Research Centre, an MRC Pathfinder Award to the University of Oxford, and the Westminster Foundation. The views expressed in this publication are those of the author(s) and not necessarily those of the NHS, the NIHR, or the Department of Health and Social Care. 
Availability of data and material Fully anonymous extracts of the data can be provided to academic research collaborators upon reasonable request, following a careful review process by the research team. The data are not publicly available due to ethical and information governance restrictions.

Code availability The code used in this analysis is available on request from the authors.

\section{Declarations}

Conflict of interest The authors have no conflicts of interest to declare that are relevant to the content of this article.

Ethics approval The University of Oxford Medical Sciences Division Research Ethics Committee provided ethical approval for the study (Ref. R62366/RE0010).

Consent to participate For students under age 16, the OxWell Survey uses an opt-out parental consent model with active assent from all students. Students aged 16 and older provide active, informed consent.

Consent for publication Not applicable.

Open Access This article is licensed under a Creative Commons Attribution 4.0 International License, which permits use, sharing, adaptation, distribution and reproduction in any medium or format, as long as you give appropriate credit to the original author(s) and the source, provide a link to the Creative Commons licence, and indicate if changes were made. The images or other third party material in this article are included in the article's Creative Commons licence, unless indicated otherwise in a credit line to the material. If material is not included in the article's Creative Commons licence and your intended use is not permitted by statutory regulation or exceeds the permitted use, you will need to obtain permission directly from the copyright holder. To view a copy of this licence, visit http://creativecommons.org/licenses/by/4.0/.

\section{References}

1. Vizard T, Sadler K, Ford T, Newlove-Delgado T, McManus S, Marcheselli F, Davis J, Williams T, Leach C, Mandalia D, Cartwright C (2020) Mental Health of Children and Young People in England. Health and Social Care Information Centre, p 1-53. Available from: https://files.digital.nhs.uk/CB/C41981/mhcyp_ 2020_rep.pdf

2. Thorisdottir IE, Asgeirsdottir BB, Kristjansson AL, Valdimarsdottir HB, Jonsdottir Tolgyes EM, Sigfusson J, Allegrante JP, Sigfusdottir ID, Halldorsdottir T (2021) Depressive symptoms, mental wellbeing, and substance use among adolescents before and during the COVID-19 pandemic in Iceland: a longitudinal, population-based study. Lancet Psychiatry 8(8):663-672. https:// doi.org/10.1016/s2215-0366(21)00156-5

3. Bignardi G, Anwyl-Irvine AL, Smith TA, Siugzdaite R, Uh S, Astle DE (2020) Longitudinal increases in childhood depression during the COVID-19 lockdown in a UK Cohort. Arch Dis Child 106(8):791-797. https://doi.org/10.1136/archdischi ld-2020-320372

4. Luijten MAJ, van Muilekom MM, Teela L, Polderman TJC, Terwee CB, Zijlmans J, Klaufus L, Popma A, Oostrom KJ, van Oers HA, Haverman L (2021) The impact of lockdown during the COVID-19 pandemic on mental and social health of children and adolescents. Qual Life Res 30(10):2795-2804. https://doi.org/10. 1007/s11136-021-02861-x

5. Magson NR, Freeman JY, Rapee RM, Richardson CE, Oar EL, Fardouly J (2021) Risk and protective factors for prospective changes in adolescent mental health during the COVID-19 pandemic. J Youth Adolesc 50(1):44-57. https://doi.org/10.1007/ s10964-020-01332-9

6. Hawes MT, Szenczy AK, Klein DN, Hajcak G, Nelson BD (2021) Increases in depression and anxiety symptoms in adolescents and young adults during the COVID-19 pandemic. Psychol Med 13:19. https://doi.org/10.1017/S0033291720005358

7. Hafstad GS, Sætren SS, Wentzel-Larsen T, Augusti E-M (2021) Adolescents' symptoms of anxiety and depression before and during the Covid-19 outbreak-A prospective population-based study of teenagers in Norway. Lancet Reg Heal Eur 5:100093. https:// doi.org/10.1016/j.lanepe.2021.100093

8. Widnall E, Winstone L, Mars B, Haworth CM, Kidger J (2020) Young People's mental health during the COVID-19 pandemic. University of Bristol: Bristol, UK. Available from: https://sphr. nihr.ac.uk/research/young-peoples-mental-health-during-thecovid-19-pandemic/

9. Penner F, Hernandez Ortiz J, Sharp C (2021) Change in youth mental health during the COVID-19 pandemic in a majority Hispanic/Latinx US sample. J Am Acad Child Adolesc Psychiatry 60(4):513-523. https://doi.org/10.1016/j.jaac.2020.12.027

10. Raw J, Waite P, Pearcey S, Shum A, Patalay P, Creswell C (2021) Examining changes in parent-reported child and adolescent mental health throughout the UK's first COVID-19 national lockdown. Preprint. PsyArxiv. Available from: https://psyarxiv.com/exktj/

11. Cost KT, Crosbie J, Anagnostou E, Birken CS, Charach A, Monga S, Kelley E, Nicolson R, Maguire JL, Burton CL, Schachar RJ (2021) Mostly worse, occasionally better: impact of COVID-19 pandemic on the mental health of Canadian children and adolescents. Eur Child Adolesc Psychiatry. https://doi.org/10.1007/ s00787-021-01744-3

12. Fisher H, Lambert H, Hickman M, Yardley L, Audrey S (2021) Experiences of the coronavirus disease-19 (COVID-19) pandemic from the perspectives of young people: Rapid qualitative study. Public Heal Pract 2:100162. https://doi.org/10.1016/j.puhip.2021. 100162

13. O'Sullivan K, Clark S, McGrane A, Rock N, Burke L, Boyle N, Joksimovic N, Marshall K (2021) A qualitative study of child and adolescent mental health during the COVID-19 pandemic in Ireland. Int J Environ Res Public Health 18(3):1-15. https://doi. org/10.3390/ijerph18031062

14. Demkowicz O, Ashworth E, O'Neill A, Hanley T, Pert K (2021) "Will my young adult years be spent socially distancing?": A qualitative exploration of UK adolescents' lockdown experiences during the COVID-19 pandemic. Prepr Res Square. https://doi. org/10.21203/rs.3.rs-451696/v2

15. Silk JS, Scott LN, Hutchinson EA, Lu C, Sequeira SL, McKone KM, Do QB, Ladouceur CD (2021) Storm clouds and silver linings: day-to-day life in COVID-19 lockdown and emotional health in adolescent girls. J Pediatr Psychol. https://doi.org/10. 1093/jpepsy/jsab107

16. Scott S, McGowan VJ, Visram S (2021) 'I'm Gonna Tell You about How Mrs Rona Has Affected Me'. Exploring Young People's experiences of the COVID-19 pandemic in North East England: a qualitative diary-based study. Int J Environ Res Public Health 18(7):3837. https://doi.org/10.3390/ijerph18073837

17. Stallard P, Pereira AI, Barros L (2021) Post-traumatic growth during the COVID-19 pandemic in carers of children in Portugal and the UK: cross-sectional online survey. BJPsych Open 7(1):1-5. https://doi.org/10.1192/bjo.2021.1

18. Dvorsky MR, Breaux R, Becker SP (2020) Finding ordinary magic in extraordinary times: child and adolescent resilience 
during the COVID-19 pandemic. Eur Child Adolesc Psychiatry 30(11):1829-1831. https://doi.org/10.1007/s00787-020-01583-8

19. Mansfield KL, Newby D, Soneson E, Vaci N, Jindra C, Geulayov G, Gallacher J, Fazel M (2021) COVID-19 partial school closures and mental health problems: a cross-sectional survey of 11,000 adolescents to determine those most at risk. JCPP Adv 1(2):e12021. https://doi.org/10.1002/jcv2.12021

20. Mansfield KL, Jindra C, Fazel M (2021) The OxWell School survey 2020: Report of preliminary findings. Available from: https://www.psych.ox.ac.uk/research/schoolmentalhealth/summa ry-report

21. Mansfield KL, Puntis S, Soneson E, Cipriani A, Geulayov G, Fazel M (2021) Study protocol: the OxWell school survey investigating social, emotional and behavioural factors associated with mental health and wellbeing. BMJ Open 11(12):1-10. https://doi. org/10.1136/bmjopen-2021-052717

22. Department for Education (2020) Supporting vulnerable children and young people during the coronavirus (COVID-19) outbreak-actions for educational providers and other partners. Available from: https:/www.gov.uk/government/publications/ coronavirus-covid-19-guidance-on-vulnerable-children-andyoung-people/coronavirus-covid-19-guidance-on-vulnerable-child ren-and-young-people

23. Gov.uk (2020) Attendance in education and early years settings during the coronavirus (COVID-19) pandemic. Available from: https://explore-education-statistics.service.gov.uk/find-statistics/ attendance-in-education-and-early-years-settings-during-thecoronavirus-covid-19-outbreak

24. Tennant R, Hiller L, Fishwick R, Platt S, Joseph S, Weich S, Parkinson J, Secker J, Stewart-Brown S (2007) The WarwickEdinburgh Mental Well-being Scale (WEMWBS): development and UK validation. Health Qual Life Outcomes 5(1):1-13. https:// doi.org/10.1186/1477-7525-5-63

25. Clarke A, Friede T, Putz R, Ashdown J, Martin S, Blake A, Adi Y, Parkinson J, Flynn P, Platt S, Stewart-Brown S (2011) WarwickEdinburgh Mental Well-being Scale (WEMWBS): mixed methods assessment of validity and reliability in teenage school students in England and Scotland. BMC Public Health 11:487. https://doi. org/10.1186/1471-2458-11-487

26. Ebesutani C, Reise SP, Chorpita BF, Ale C, Regan J, Young J, Higa-McMillan C, Weisz JR (2012) The Revised Child Anxiety and Depression Scale-Short Version: scale reduction via exploratory bifactor modeling of the broad anxiety factor. Psychol Assess 24(4):833-845. https://doi.org/10.1037/a0027283

27. Chorpita BF, Ebesutani C, Spence SH (2020) Revised Children's Anxiety and Depression Scale: User's Guide. Available from: https://www.childfirst.ucla.edu/wp-content/uploads/sites/163/ 2018/03/RCADSUsersGuide20150701.pdf

28. Arseneault L (2018) Annual research review: the persistent and pervasive impact of being bullied in childhood and adolescence: implications for policy and practice. J Child Psychol Psychiatry 59(4):405-421. https://doi.org/10.1111/jcpp.12841

29. Fazel M, Hoagwood K, Stephan S, Ford T (2014) Mental health interventions in schools in high-income countries. Lancet Psychiatry 1(5):377-387. https://doi.org/10.1016/S2215-0366(14) 70312-8
30. West P, Sweeting H (2003) Fifteen, female and stressed: changing patterns of psychological distress over time. J Child Psychol Psychiatry 44(3):399-411. https://doi.org/10.1111/1469-7610.00130

31. Högberg B, Strandh M, Hagquist C (2020) Gender and secular trends in adolescent mental health over 24 years-The role of school-related stress. Soc Sci Med 250:112890. https://doi.org/ 10.1016/j.socscimed.2020.112890

32. Becker SP, Gregory AM (2020) Editorial perspective: perils and promise for child and adolescent sleep and associated psychopathology during the COVID-19 pandemic. J Child Psychol Psychiatry 61(7):757-759. https://doi.org/10.1111/jcpp.13278

33. Marlow R, Goodman R, Meltzer H, Ford T (2013) Influence of problematic child-teacher relationships on future psychiatric disorder: population survey with 3-year follow-up. Br J Psychiatry 202(5):336-341. https://doi.org/10.1192/bjp.bp.112.120741

34. Orben A, Tomova L, Blakemore SJ (2020) The effects of social deprivation on adolescent development and mental health. Lancet Child Adolesc Health 4(8):634-640. https://doi.org/10.1016/ S2352-4642(20)30186-3

35. Loades ME, Chatburn E, Higson-Sweeney N, Reynolds S, Shafran R, Brigden A, Linney C, McManus MN, Borwick C, Crawley E (2020) Rapid systematic review: the impact of social isolation adolescents in the context of COVID-19. J Am Acad Child Adolesc Psychiatry 59(11):1218-1239. https://doi.org/10.1016/j.jaac. 2020.05.009

36. Armitage R (2021) Bullying during COVID-19: the impact on child and adolescent health. Br J Gen Pract 71(704):122. https:// doi.org/10.3399/bjgp21X715073

37. Arseneault L, Bowes L, Shakoor S (2010) Bullying victimization in youths and mental health problems: Much ado about nothing? Psychol Med 40(5):717-729. https://doi.org/10.1017/S003329170 9991383

38. Gregory AM, Sadeh A (2016) Annual research review: sleep problems in childhood psychiatric disorders-A review of the latest science. J Child Psychol Psychiatry 57(3):296-317. https://doi. org/10.1111/jcpp.12469

39. Lim MT, Ramamurthy MB, Aishworiya R, Rajgor DD, Tran AP, Hiriyur P, Kunaseelan S, Jabri M, Goh DY (2021) School closure during the coronavirus disease 2019 (COVID-19) pandemicImpact on children's sleep. Sleep Med 78:108-114. https://doi. org/10.1016/j.sleep.2020.12.025

40. Murray J (2020) Lancashire school puts Covid catch-up on hold for wellbeing in wellies. The Guardian. Available from: https:// www.theguardian.com/education/2021/mar/23/lancashire-schoolputs-covid-catch-up-on-hold-for-wellbeing-in-wellies

41. The Scottish Government (2020) Coronavirus (COVID-19): Curriculum for Excellence in the Recovery Phase. Available from: https://www.gov.scot/publications/coronavirus-covid-19-curri culum-for-excellence-in-the-recovery-phase/

42. Pearcey S, Raw J, Shum A, Waite P, Creswell C (2020) Supplementary Report 07: Regular communication with friends outside the household during full lockdown and in the following months when restrictions were eased. Available from: https://cospaceoxf ord.org/wp-content/uploads/2020/10/Co-SPACE-supplementaryreport-07-DfE.pdf 